\title{
MARGUERITE DURAS, UM CORPO DE DOR
}

Marcela Filizola

(iD) https://orcid.org/0000-0003-2966-1446

Como citar este artigo: FILIZOLA, M. Marguerite Duras, um corpo de dor. Todas as Letras - Revista de Lingua e Literatura, São Paulo, v. 22, n. 1, p. 1-13, jan./abr. 2020. DOI: 10.5935/1980-6914/eLETLT2011537

Submissão: maio de 2018. Aceite: maio de 2019.

Resumo: Este artigo busca observar como o desfazimento do sujeito e as quebras na lógica racional da linguagem podem levar a aberturas para novas subjetividades diante de situações de desamparo em que o corpo já não parece mais habitado pelo eu. Com base, principalmente, no texto A dor, de Marguerite Duras, um diário da época da Segunda Guerra, porém publicado apenas em 1985, em que a autora relata o período de espera por seu companheiro detido em um campo de concentração, a análise procura refletir a respeito da solidão e do desespero da escrita no momento de vigília, indagando de que modo a escritora trabalha essas questões na própria materialidade da língua.

Palavras-chave: Marguerite Duras. Corpo. Escrever. Linguagem. Subjetividade. 


\section{UM CORPO GUE ESCREVE}

$\mathbf{A}$

escrita sem nome não é uma escrita sobre o que não tem nome; é uma escrita que perde o nome justamente ao buscar meios de furar a linearidade narrativa para falar do desconhecido, do não saber. Entretanto, segue também por chão incerto, um percurso desviante que se faz na caminhada e que inscreve os gestos tateantes de uma experiência tanto de solidão quanto de abertura. Essa escrita cria encontros que rasgam a noção do próprio, propondo relações que não se definem pela busca de uma totalidade e que se fazem continuamente no exercício de presença e de escuta, no qual, simultaneamente, preserva-se e perde-se algo de si mesmo.

Por isso, talvez, Marguerite Duras (1914-1996) diga: não é uma escrita apesar do desespero, e sim com o desespero, com a dor e o desfazimento. Seria possível pensarmos que há um movimento nessa escrita em direção a diferentes noções de subjetividade que se afastam da construção de um sujeito soberano e fechado em si. Segundo comenta Cixous em entrevista a Foucault, o que observamos em Duras é uma perda sem fim: "O trabalho que ela faz é um trabalho de perda; como se a perda fosse inacabável; é muito paradoxal. Como se a perda jamais fosse perdida o bastante, você sempre tem a perder" (FOUCAULT, 2001, p. 358). Ainda assim, a perda não deve ser lida como uma destruição negativa ou total. Perde-se algo, sim, mas isso possibilita outra forma de ser-estar-pensar, outra forma de viver junto. Uma das questões que perpassa a escrita de Duras parece ser o que fazer a partir dos restos, e uma possivel resposta é dada por Evelyne Grossman (2006, p. 34-35), uma vez que, da perda, talvez outra escrita, não nomeada, possa ser inventada:

A destruição luta contra a forma cristalizada do sentido, a forma acabada, total, o círculo. [...] A perda não é portanto puramente o abandono. Destruir não é simplesmente desfazer, demolir, e sim inventar na escrita um outro espaço do corpo e do afeto que não mais se separe do pensamento sobre o afeto.

Em Escrever, texto criado e também filmado na casa de Duras de Neauphle-le-Château, presente no livro de título homônimo, a autora discorre sobre o processo de escrita e sobre a solidão enfrentada diante deste movimento rumo ao desconhecido:

[...] dentro da casa a gente fica tão só que às vezes se perde. Só agora sei que permaneci na casa dez anos. Sozinha. E para escrever livros que mostraram, para mim e para os outros, que eu era a escritora que sou. Como isso aconteceu? E como isso pode ser expresso? O que posso dizer é que o tipo de solidão que há em Neauphle foi feito por mim. Para mim. E que é apenas dentro dessa casa que fico só. Para escrever. Não para escrever como havia feito até então. Mas para escrever livros desconhecidos para mim, e nunca previamente determinados, por mim nem por ninguém (DURAS, 1994, p. 13).

Nessa passagem, podemos aproximar o pensamento de Duras do conceito de solidão essencial trabalhado por Blanchot (2011, p. 11) em O espaço literário, texto no qual ele elabora de que modo a solidão da escrita diferencia-se do "isolamento complacente do individualismo". Seria, então, uma solidão que surge em se desabitar como indivíduo para se fazer - e para escrever - com os outros (DURAS, 1974, p. 157). Em Boas falas, um livro de conversas entre Marguerite 
Duras e Xavière Gauthier (1974, p. 49), a escritora comenta que o esquecimento de si que se inscreve na escrita é um "sequestro de nós mesmos", o que geralmente ocorre quando enfrentamos situações-limites, e observa que isso poderia levar a um vazio, assim como a uma abertura da qual surgiria a escrita.

Em seus textos, notamos como os pronomes eu e ela confundem-se e misturam-se, dando a ver o esvaziamento de si e a abertura ao outro, pois o eu parece se tornar mais presente ao se colocar como outro. Há um desencaixe do corpo e um desencontro com o próprio ser que comparecem no processo de escrita de Duras, de modo que não existe a afirmação do indivíduo, e sim o desespero diante de vidas que se colocam de forma incerta e indefinida, confirmando no ato de escrever algo que "está inteiramente privado de si" (BLANCHOT, 2011, p. 17). O desespero diante da força devastadora da escrita procura um corpo-linguagem que não se acomoda, que busca novos desvios para não se fixar:

Isso torna a escrita selvagem. Vai-se ao encontro de uma selvageria anterior à vida. [...] Não se pode escrever sem a força do corpo. É preciso ser mais forte do que si mesmo para abordar a escrita. É uma coisa gozada, sim. Não é apenas a escrita, o escrito, é o grito das feras noturnas, de todos, de você e eu, os gritos dos cães (DURAS, 1994, p. 22-23).

Embora Duras aponte para a selvageria da escrita, ou seja, para uma experiência que é violenta e que necessita de coragem e de "corpo" para ser enfrentada, a inquietação que leva uma autora a escrever parece ser também um modo de sobrevivência, como se a única maneira de lidar com aquilo que continuamente perdemos fosse escrevendo. Ainda que seja devastador, escrever permite que algo se preserve, não como um traço pessoal, mas como uma experiência compartilhada, fazendo com que seguir adiante se torne possivel, mesmo que esse movimento de avanço talvez fuja à linearidade narrativa. A escrita, portanto, parece ser um processo e um fracasso, assim como uma perda inacabável, e, por esse motivo, sempre recomeça:

O que atrai o escritor, o que impulsiona o artista não é diretamente a obra, é sua busca, o movimento que conduz a ela [...]. E o escritor, frequentemente, não deseja acabar quase nada, deixando em estado de fragmentos cem narrativas que tiveram a função de conduzi-lo a determinado ponto, e que ele deve abandonar para tentar ir além desse ponto (BLANCHOT, 2005, p. 291).

\section{O CORPO ESTRANHO D'A DOR}

Neste artigo, busco observar de que modo essas questões comparecem em A dor, um texto diarístico escrito na época da Segunda Guerra Mundial (19391945), porém publicado apenas na década de 1980, que relata a espera de Marguerite Duras por Robert Antelme (1917-1990), seu marido, que fora preso e deportado pela Gestapo para um campo de concentração. Embora esteja em forma de diário, o que encontramos, conforme comenta Rosana Kohl Bines (2015) a respeito desse mesmo texto, "é um permanente arrastar-se para fora do mundo interior e não, como se poderia supor, um mergulho subjetivo nas dores do eu". Então, a leitura aqui proposta não irá refletir sobre $A$ dor por um viés confessional, no qual veríamos a revelação de um sujeito e de sua interioridade, e sim pelo viés de uma escrita de desfazimento e perda, como mencio- 
nado, o que levaria a um refazimento da própria noção de vida, ou seja, ao que chamo de sobrevida.

Logo nas primeiras páginas de "Escrever", além de falar sobre a solidão da escrita, Duras (1994, p. 13-14) também descreve sua relação com a passagem de tempo, sublinhando o marco que foi o período de espera por Robert:

Compreendi que eu era uma pessoa sozinha com a minha escrita, sozinha $e$ muito distante de tudo. Isso durou dez anos, talvez, não sei mais, raramente contei o tempo que passei escrevendo e qualquer outro tempo. Contei o tempo que passei esperando por Robert Antelme e Marie-Louise, sua jovem irmã. Depois, não contei mais nada.

Esse trecho nos dá uma indicação sobre a temporalidade que encontramos em $A$ dor: um tempo constantemente contado, pois cada dia que passa é mais um dia sem notícias do paradeiro de Robert Antelme. Contudo, é igualmente um tempo marcado por esquecimentos e repetições; é um tempo de suspensão diante do desespero e da fragilidade do corpo em estado de vigília, uma vez que não é possivel pensar no futuro nem em avanços enquanto essa ausência ocupa toda a vida de M. Duras.

Devido ao estado de suspensão, podemos pensar a respeito do corpo de dor, de desespero e de solidão que se inscreve no diário menos como eu e mais como ela, ou como outro - um corpo intruso, estrangeiro. Parece ser preciso que a autora/narradora se desfaça de seu lugar de sujeito para que possa viver tanto a experiência de espera por Robert Antelme quanto a da escrita. Para salvar a própria vida, para encontrar uma sobrevida - que já não seria mais a vida anterior ao desastre da guerra -, o corpo deve ser ocupado, pois esse estranho que se afasta do eu é quem contém um impulso de vida para enfrentar o constante embate com a morte que acompanha as linhas d'A dor. Esse gesto de escrita aproxima-se da noção de saúde frágil da qual fala Deleuze (2011, p. 14), quando movimentos menores são necessários para dar a ver aquilo que é forte demais:

A literatura aparece, então, como um empreendimento de saúde: não que o escritor tenha forçosamente uma saúde de ferro (haveria aqui a mesma ambiguidade que no atletismo), mas ele goza de uma frágil saúde irresistível, que provém do fato de ter visto e ouvido coisas demasiado grandes para ele, fortes demais, irrespiráveis, cuja passagem o esgota, dando-lhe contudo devires que uma gorda saúde dominante tornaria impossíveis.

Ao abordar, por meio da escrita, experiências "irrespiráveis", que nos tiram de nós, Duras não busca apaziguar ou anular a dor e o desespero, e sim conviver com isso, de modo a "Morrer apenas o estritamente necessário, sem ultrapassar a medida. / Renascer o tanto preciso a partir do resto que se preservou", como escreve Wislawa Szymborska no poema "Autotomia" (1972). Este "não morrer demais" da poeta é o que busco pensar como uma sobrevida, o que se assemelha a um trecho no fim de $A$ dor: "Agora, a esperança está inteira, a dor implantada na esperança. Às vezes me espanto por não morrer: uma lâmina gelada profundamente enterrada na carne viva, de noite, de dia, e mesmo assim sobrevivemos" (DURAS, 1986, p. 73).

Uma das coisas que resta do corpo marcado pela dor, porém sobrevivente, é a proximidade com a morte que não pode ser apagada nem recalcada, como a lâmina enterrada na pele. Entretanto, a partir da paralisia e da incerteza, surge 
também uma abertura: um outro modo de se colocar na vida. O apagamento da primeira pessoa e a fragilidade do corpo com os quais deparamos nas páginas do diário sugerem uma escrita cuja força está em desacomodar dicotomias. Vida e morte, dentro e fora, razão e sensação misturam-se em uma experiência de escrever que não propõe a constituição do indivíduo diante do desastre, mas seu desfazimento, para que dê espaço a outras subjetividades, ressignificando principalmente a oposição entre eu e outro. De forma um pouco selvagem, isto é, afastando-me do sentido das ideias desses dois escritores, cito Blanchot (2013, p. 20-21) ao falar de Bataille para aqui pensarmos sobre M. Duras:

O que é, pois, que me coloca mais radicalmente em causa? Não minha relação comigo mesmo como finito ou como consciência de ser na morte ou para a morte, mas a minha presença para outrem enquanto este se ausenta morrendo. Manter-me presente na proximidade de outrem que se distancia definitivamente morrendo, tomar sobre mim a morte de outrem como a única morte que me concerne, eis o que me põe para fora de mim e é a única separação que pode me abrir [...].

Considerando o trecho acima e a afirmação de Deleuze (2011, p. 12) de que "A sintaxe é o conjunto de desvios necessários criados a cada vez para revelar a vida nas coisas", podemos indagar de qual maneira a linguagem de A dor - uma linguagem do fora de si, do encontro com o outro e com a morte - torna material a ansiedade que atravessa o corpo que escreve. O desespero comparece no texto nos constantes movimentos de vaivém da narradora que marcam tanto o momento de suspensão da espera quanto a sensação de impotência. A própria Duras comentou que sua preocupação ao escrever não era dar um sentido àquilo, e sim criar textos em decomposição, como se estivessem com falta de ar (apud GROSSMAN, 2006, p. 35), e o que encontramos no diário desse período de vigília não é uma descrição da angústia enfrentada diante da situação de desamparo causada pela falta de notícias do paradeiro de Robert. Como destacado na epígrafe do artigo, é uma escrita com desespero que se materializa na linguagem. Deparamos com uma escrita na qual falta ar. Por isso, parece haver uma tentativa, por meio de frases curtas que muitas vezes se repetem, de controlar a respiração para acalmar o corpo. É bastante perceptivel a dificuldade de encadeamento do pensamento para a construção de uma narrativa, e o intuito talvez seja justamente este: não construir uma narrativa, mas mostrar sua quase impossibilidade. Não seria, portanto, a impossibilidade de dizer, e sim uma impossibilidade de dizer de outra forma, uma que não seja a da escrita cortada e engasgada, conforme observado no artigo "Longe dele, longe dela":

O desempenho verbal do texto soa como uma série de engasgos em câmera lenta. A linguagem deambula, mas de forma interruptiva, recomeçando a cada vez, sem sair propriamente do lugar, sem abandonar jamais o núcleo duro $e$ ausente que ela sabe tatear em vão. Há uma vigilância extrema para que, no ato de escrita, nada escape do composto de gestos e afecções ligados ao estado de espera (BINES, 2015).

A escrita semelhante à lentidão de uma câmera parece querer capturar a necessidade de "não fazer muitos movimentos, não desperdiçar energia" (DURAS, 1986, p. 10), como se, ao poupar o próprio corpo, estivesse poupando também o corpo de seu companheiro. Diante dos escombros espaço-temporais causados 
pela guerra, diante da força destruidora dessa experiência que invade a vida, não há linearidade construtiva. Ao materializar na sintaxe do texto a paralisia física da espera, um outro tipo de avanço emerge, como aponta Gauthier nas conversas com M. Duras:

Em seus livros, justamente, não se avança. Creio que há também a questão do movimento. Os movimentos são amiúde muito imperceptíveis, escorregadios, assim, e não se trata de forma alguma de uma questão de avanço. Quero dizer, não há caminhada, ou então é uma caminhada em círculos (DURAS, 1974, p. 14).

Além da narrativa estagnada, que avança em círculos, podemos notar a falta de lugar da narradora em $A$ dor, o que tanto tem a ver com sua situação de vigília enquanto já se comemora o fim da guerra em Paris quanto tem a ver com a solidão da própria escrita. Observamos isso nas páginas do diário por meio da mistura dos espaços interiores com os exteriores. Na abertura do texto, há uma narradora que parece se definir pelos cômodos no entorno, por aquilo que pode ser visto na casa, como se houvesse uma espacialização do eu: "Na frente da lareira, o telefone, a meu lado. À direita, a porta da sala e o corredor. No fundo do corredor, a porta de entrada" (DURAS, 1986, p. 9). A caracterização da casa não é gratuita, pois é lá que Duras enfrenta a aflição da espera, podendo perder-se ao imaginar as cenas da morte de Robert: "Deixo o centro por volta das cinco da tarde, passo pelo cais. O tempo está ótimo, é um belo dia de sol. Tenho pressa de chegar em casa, de me trancar com o telefone, reencontrar a vala escura" (DURAS, 1986, p. 28). Podemos ver um duplo movimento na relação com a casa. Por um lado, há uma necessidade de ir à rua para fugir das cenas de morte criadas no interior, como demonstra esta passagem: "Em certas ocasiões, a imagem fica mais intensa, então grito ou saio e ando por Paris" (DURAS, 1986, p. 29). Entretanto, por outro, há também uma sensação de não pertencimento diante das vidas que seguem despreocupadas após o fim da guerra: "Ninguém tem nada em comum comigo. A rua. Pessoas riem em Paris, nesse momento, sobretudo os jovens. Eu tenho apenas inimigos" (DURAS, 1986, p. 12); ou ainda: "Sai, a paz me pareceu iminente. Voltei para casa depressa, perseguida pela paz. Pressenti a chegada de um futuro possivel, que uma terra estranha, onde ninguém espera, ia emergir do caos" (DURAS, 1986, p. 57).

Percebe-se, então, que o desconforto não ocorre apenas nos momentos em que M. Duras se vê fora de casa, em contato com a alegria que toma as ruas de Paris, mas também quando está em casa sem aguentar mais "a vala escura" e precisando sair. Ao lermos A dor, constatamos que ela simplesmente não consegue encontrar tranquilidade enquanto espera, pois seria impossivel voltar a habitar sua vida sem antes saber do companheiro. Embora seja um texto cheio de saltos temporais e delírios febris, o diário marca também um período em que Duras contou a passagem de tempo, como citado no início deste artigo. Afinal, o tempo corria, porém sem trazer um futuro. O contar das horas era justamente uma continuação do momento presente representado pela ausência e pela vala escura, ou seja, pela morte que se fazia certa diante da incerteza e da falta de notícias. Acredito que o texto dê a ver a ruína dos espaços dicotômicos ao inscrever um corpo sem lugar, desabitado e estrangeiro conforme circula pelas ruas, mas igualmente estrangeiro em sua solidão dentro de casa. É um corpo que está fora da própria vida, como se não houvesse mais vida para ocupar diante da possibilidade de morte de uma pessoa amada. Podemos notar no texto "a desconexão radical de uma mulher de sua vida rotineira, bruscamente paralisada e 
dali em diante devotada tão somente à vigília pelo retorno do companheiro deportado" (BINES, 2015).

A relação que havia entre Marguerite Duras e Robert Antelme antes da deportação faz com que exista uma ligação entre a vida que aguarda e aquela que está no campo de concentração, como a própria autora escreve: "Estamos presos por um outro encadeamento: aquele que liga os corpos deles a nossa vida" (DURAS, 1986, p. 42). Aqueles que ficaram são retirados da esfera da lógica comum para entrar em um estado de vigília, e o encadeamento dos dois corpos parece levar Marguerite a impor à própria carne a violação vivida pelo companheiro. Ao pressupor os horrores enfrentados por Robert, ela não dorme, não come, delira, tem febre: "Um minuto de ar respirável. Sentamos para comer. A vontade de vomitar chega imediatamente. O pão é aquele que ele não comeu, cuja falta provocou sua morte" (DURAS, 1986, p. 15). A espera por um ente querido faz com que não só ela precise se anular, mas também precise lutar por sua vida como única esperança de que ele esteja fazendo o mesmo, como se a sobrevivência dela fosse garantir a vida de Robert Antelme. A meu ver, existe uma necessidade de mimetizar tanto a dor que Duras o imagina vivendo quanto a garra por seguir.

Na escrita diarística, observa-se uma aproximação entre as situações cotidianas e a impossibilidade de controlar a volta de Robert. Durante a vigília, a vida de M. Duras se faz simultaneamente destes dois momentos que se misturam a todo instante: as cenas diárias e as cenas da provável morte do companheiro. Apesar de a espera ocupar toda a vida dela, são os pequenos detalhes do dia a dia - coisas que parecem insignificantes para ela que tem acesso àquilo - que a fazem pensar nas privações sofridas por Robert, conforme vemos nesta citação: "Daria a minha vida por ele. Não posso lhe dar um pedaço de pão" (DURAS, 1986, p. 42). Do mesmo modo, quando chega a notícia de que ele está vivo, o fim da angústia pela morte e pela guerra invade o momento cotidiano - "O gosto do café quente: ele vive" (DURAS, 1986, p. 47) -, como se ela enfim estivesse presente e sentisse o gosto do café. As imagens e sensações rotineiras presentes no texto parecem demonstrar as violações que acometem certas vidas, pois, ao perceber que o companheiro não tem o mínimo, surge a constatação de que ele não tem quase nada, talvez não tenha nem mesmo o necessário para garantir sua sobrevivência. Ao poder tomar um café quente, ao poder comer um pedaço de pão, Duras encontra-se em um estado de segurança que foge àquele dos que estão em situações de precariedade. Os pequenos gestos cotidianos vão cavando um abismo onde o corpo dela se enterra, juntando-se à cena que ela cria do corpo de Robert na vala escura.

Enquanto espera, a escritora se afasta de todos, inclusive de si, e só poderá voltar a habitar a própria vida e recuperar seu nome, negado por ela mesma em alguns momentos de A dor - "Grito que não. Que meu nome é um horror" (DURAS, 1986, p. 37) -, quando tiver uma resposta, seja essa a sobrevivência do marido ou a confirmação de sua morte. O pensamento de Duras é atingido diversas vezes pela certeza da morte de Robert, exteriorizando a necessidade desesperada de uma resposta, qualquer que seja, mesmo sabendo que isso não permitirá uma volta incólume à própria vida. Será uma outra espécie de vida, uma na qual essa experiência jamais poderá ser esquecida.

Ainda assim, pensar no não esquecimento contradiz de certo modo o prefácio de $A$ dor, levando em consideração que Duras diz não se recordar dessa escrita, diz não saber como poderia ter escrito isso enquanto esperava por Robert Antelme, 
diz não lembrar como ou onde escreveu o diário, tendo-o esquecido completamente apenas para encontrá-lo décadas depois. Há até mesmo uma recusa das palavras "literatura" e "escrito" ao deparar com essas páginas, embora ela reconheça a própria letra e as coisas ali mencionadas:

A dor é uma das coisas mais importantes de minha vida. A palavra "escrito" não seria adequada. Encontrei-me diante de páginas metodicamente repletas de uma letra extraordinariamente regular e calma. Encontrei-me diante de uma fenomenal desordem do pensamento e do sentimento que não ousei tocar, $e$ comparada à qual a literatura me envergonha (DURAS, 1986, p. 8).

Seria pouco produtivo questionar a veracidade ou a sinceridade do que M. Duras escreve no prefácio do diário. Contudo, talvez seja importante refletirmos sobre o porquê do dito esquecimento de um texto que ela mesma afirma ser "das coisas mais importantes" de sua vida. Não creio que haja realmente uma negação da literatura nessas palavras, e sim uma busca por novas experiências literárias que acolham a precariedade após a destruição e a perda, possibilitando que novas vozes e escutas possam surgir. A escrita contrasta a "letra extraordinariamente regular e calma" que aparece no papel com uma "fenomenal desordem do pensamento e do sentimento" que vemos no corpo, colocando essa relação como cerne da questão. O que observamos são gestos indicativos de outros espaços de escrita que a própria Duras não sabia nomear, apesar de tentar descrevê-los em diversos textos, como em "A morte do jovem aviador inglês", que também faz parte do livro Escrever: "Haverá uma escrita da não-narrativa. Um dia isto virá. Uma escrita breve, sem gramática, uma escrita de palavras sozinhas. Palavras sem apoio de uma gramática. Extraviadas. Ali, escritas. E logo deixadas de lado" (DURAS, 1994, p. 63).

Retomando a questão do esquecimento presente no diário, parece pertinente perguntar: é necessário esquecer ou abandonar a experiência de choque vivida para que se possa seguir adiante? Segundo uma passagem de $A$ dor, foi isso que a própria sociedade fez em relação à guerra: "A paz já se faz notar. Como se fosse uma noite profunda, também o início do esquecimento" (DURAS, 1986, p. 57). Ou seja, não é de fato um esquecimento, mas talvez uma tentativa de distanciamento da dor para que seja possivel seguir vivendo. Talvez fosse preciso se afastar da escrita do diário, conforme mencionado no prefácio, exatamente por ter sido algo que a assombrou. Podemos então retornar à reflexão do início do artigo acerca do diário como uma experiência íntima que não deve ser pensada como uma revelação interior, e sim como uma experiência de inscrição em meio ao abandono do eu. Duras traz um pensamento, ou um saber, do corpo para o que escreve, enfatizando o processo de inscrição não somente como um rasgo no papel, mas também na pele, como uma via de sobrevivência e de refazimento em meio à perda de si e do outro e em meio à desfiguração corporal - tanto da própria Marguerite quanto de Robert ao voltar para casa.

A escrita com a qual deparamos em $A$ dor sugere ter sido algo que surgiu de forma involuntária, como se fossem sensações do corpo, o que a difere da construção racional de uma narrativa:

O texto parece correr em piloto automático, como se não possuísse senso de direção ou roteiro. Há saltos expressivos entre uma e outra sentença, agravando a sensação de um jorro incontido de palavras, que escapam ao controle do emissor (BINES, 2015). 
Esse descontrole que foge à norma parece procurar uma forma que se afaste da linguagem da razão falada pelos homens - uma língua que se torna estrangeira para aquelas mulheres em vigilia. Isso pode ser observado na passagem em que um padre que havia sido preso retorna com uma criança alemã órfã para o centro onde mulheres esperam por notícias de seus maridos. O homem diz a elas que é preciso perdoar, pois a criança não tem culpa das atrocidades da guerra, falando "Indiferente à dor, à espera", permitindo-se "perdoar, absolver, ali, imediatamente, ato contínuo [...]" (DURAS, 1986, p. 30). Contudo, como lemos no diário, esses argumentos lógicos são uma língua incompreensivel para quem permanece em vigilia: "Tudo se dividia. De um lado, a frente das mulheres, compacta, irredutivel. E do outro, aquele único homem a ter razão, numa linguagem que as mulheres não mais entendiam” (DURAS, 1986, p. 30).

O pensamento é tomado pela não razão e pelo caos, pois resta apenas "sofrimento, gritos e sangue” (DURAS, 1986, p. 43). O corpo e o pensar são abandonados para ser ocupados pela dor não só da ausência de Robert, mas da indefinição com relação à vida por vir. Ao se abster da vida, cria-se um espaço para outra consciência: a consciência da dor. No momento de suspensão, quando o pensamento falta (DURAS, 1986, p. 42), essa é a personagem que assume a vida de Duras (e, posteriormente, a de Robert em seu retorno): "A dor é tanta, ela sufoca, está sem ar. A dor precisa de espaço” (DURAS, 1986, p. 12). Nota-se na passagem como a dor adquire o lugar de sujeito gramatical. Além disso, não é uma dor que alguém sente, mas a dor - não importa de quem, talvez de todos; é uma dor que se mistura à voz da narradora, levando-nos a indagar "quem sufoca? quem está sem ar?" -, e a necessidade de espaço permite uma abertura para uma escrita do outro, na qual observamos uma recusa do eu. Há um apagamento do indivíduo, ou um esvaziamento do sujeito, através dos jorros do corpo, colocando a escrita como um duplo movimento de fracasso do sujeito e de inscrição de si mesmo, porém já como outro, já como um estranho para um eu soberano. Uma escrita de dor e de imobilidade parece necessária para que seja possivel sobreviver de outra forma, na qual o eu se coloca também como outro.

Enquanto a materialidade do corpo continua existindo, quem o habita já não é Marguerite. Talvez naquele momento de espera ela tenha tido que criar outra corporeidade, habitando as páginas do diário, o corpo da letra, e inscrevendo-se ali como outra, considerando que são páginas das quais ela diz nem se lembrar de ter escrito. Em inúmeras passagens, os membros do corpo parecem estranhos para ela, como se não pudessem ser controlados, ou como se ela nem mesmo soubesse que se trata de seu corpo. Destaco dois trechos em que isso pode ser notado: "Não sei se estou com sono. Já faz algum tempo que não sinto mais sono. Acordo, e aí sei que dormi" (DURAS, 1986, p. 32) e "A cabeça contra a vidraça. Devo ser eu quem está chorando" (DURAS, 1986, p. 35). Em outro momento, observamos que as partes do corpo são irreconheciveis, tornando-se praticamente pesos mortos: "É bom ficar com a testa encostada na vidraça fria. Não posso mais aguentar o peso da cabeça. As pernas e os braços estão pesados, mas muito menos que a cabeça. Deixou de ser uma cabeça, é um abscesso" (DURAS, 1986, p. 34). O estranhamento do próprio corpo leva a outra apreensão de vida. O que resta é um corpo intruso, mas que não a deixa se abandonar completamente, mesmo que ela não aguente mais: "Não sei mais onde me enfiar para aguentar" (DURAS, 1986, p. 21). Transformando-se em um recipiente passivo tomado por forças que não podem ser controladas (febres, 
cansaços, gritos de desespero), o corpo da narradora ora está inerte, ora se move sem parar, como se apenas conseguisse se colocar em movimento quando impulsos externos o atingem: "Tudo está chegando ao fim. Não consigo parar de andar" (DURAS, 1986, p. 13).

\section{UM CORPO QUE SOBREVIVE}

E, no entanto, não se chega ao fim. Novamente é retomada a ideia de que o movimento de vida é também um movimento de aproximação da morte, porque expõe o risco constante do viver. Essa proximidade faz emergir um novo corpo, que carrega algo desconhecido, como se a estrutura anterior já não fosse mais possivel. Após o retorno de Robert Antelme, Duras questiona o que é a coisa desconhecida presente na própria carne e nas entranhas de seu marido, que ainda está diante do risco de morte depois da experiência do campo de concentração: "Dizíamos talvez ali, sob nossos olhos, ele estivesse comendo o figado, o baço. Como saber? Como saber o que ainda havia naquela barriga de desconhecido, de dor?" (DURAS, 1986, p. 69). Há algo novo e estranho que permanece no corpo e que talvez o faça sobreviver. Em $A$ dor, observamos perdas que não se dão de uma só vez, e sim como lascas tiradas da carne, do pensamento e da linguagem a cada dia, aproximando o sujeito de um desfazimento às vezes difícil de ser sustentado, mas que pode criar fissuras que possibilitem outras subjetividades. A pele e a escrita laceradas, assim como o pensamento afásico e a perda do nome, fazem com que se avance de diferentes maneiras. O que resta diante da dor e da catástrofe é um corpo esvaziado de razão, ocupado pela fome e por ações involuntárias - ocupado pelo desejo de sobrevivência.

Diferentemente do abandono vivido por M. Duras, cujo corpo parece ganhar vida própria no momento de espera, seguindo quase contra a vontade da escritora, Robert quer lutar para viver, mas seu corpo quase cede: "O rosto estava coberto por uma dor muda e intensa porque o alimento ainda the era negado, tudo continuava como no campo de concentração" (DURAS, 1986, p. 65). A princípio, quando ainda está entre a vida e a morte, ele é uma "forma", um resto de corpo humano que mal pode ser reconhecido: "Não o reconheço. Ele me olha. Sorri. [...] É por esse sorriso que, de repente, o reconheço, mas de muito longe, como se o visse no fim de um túnel. [...] E depois o sorriso desaparece. Ele volta a ser um desconhecido" (DURAS, 1986, p. 64). Vemos nessa passagem a dificuldade do retorno, pois não só é preciso não morrer, mas também é preciso encontrar um modo de cavar uma vida na sobrevivência. Como preservar algo da vida anterior à experiência do campo de concentração? Como não retornar inteiramente outro? E, ainda assim, há algum resto de si, visto em seu sorriso, que se preserva. Mesmo que seja apenas um lampejo, talvez seja a partir desse minimo que rapidamente desaparece que uma maneira de seguir e de sair da vala escura se torne possivel.

A dor dá a ver um corpo desencaixado, à beira da morte, com febre, com diarreia; ou seja, é uma linguagem que jorra assim como o corpo jorra na tentativa de viver. Quando Duras escuta que seu companheiro não morreu, percebemos que a vida irrompe do corpo dela, como se o corpo fosse estranho à escritora: "Algo se rompe, sai pela boca, pelo nariz, pelos olhos. Precisa sair. [...] Jorra como se fosse água, sai por todos os poros" (DURAS, 1986, p. 46). O choro a toma porque não é mais possivel guardar algo dentro de si (DURAS, 1986, p. 37). 
Em diversos trechos, há uma mistura dos pronomes eu e ela (DURAS, 1986, p. 44-46), como se Duras se visse fora de si nos momentos de jorro, para então poder retornar, embora já não seja uma volta ao mesmo.

Há um momento em Boas falas em que a autora comenta a respeito da menstruação como "vida demais" (DURAS, 1974, p. 115), e talvez seja possivel pensarmos nas coisas que jorram de todos os orificios n'A dor como uma luta pela sobrevivência através dos excessos do corpo. Seria preciso que o corpo se vulnerabilizasse, transbordasse e ficasse mais enfraquecido ao colocar para fora seus jorros para (sobre)viver? Ao retornar, apesar da precariedade física, Robert não para de falar e contar o que viveu. Em outra passagem, Duras escreve a respeito de uma jovem grávida que ela havia visto na fila do centro para buscar os pertences do marido fuzilado, dizendo que, enquanto esperava, a mulher também não conseguia parar de falar, como se a guerra precisasse transbordar para que a vida pudesse seguir, para que aquela nova vida pudesse nascer (DURAS, 1986, p. 36-37). A meu ver, a fragilidade que aparece no diário não deve ser lida pelo viés da fraqueza, e sim como aquilo que os mantém vivos, como um modo de expelir a guerra para então buscar uma reorganização do corpo.

A sobrevivência de Robert Antelme retira Marguerite Duras do estado de suspensão. Ela escreve "As forças voltam", "Vamos viver" (DURAS, 1986, p. 72). O que resta é a esperança e não mais a espera. Contudo, a dificuldade que acompanha o texto desde as primeiras páginas é a impossibilidade de voltar à vida anterior. Duras (1986, p. 35) menciona constantemente que morrerá após o retorno de seu companheiro e, mesmo depois da volta de Robert, ela ainda deseja a própria morte, ainda deseja algo que a tire do estado de pavor do qual não consegue se desvencilhar: "Minha identidade deslocou-se. Sou apenas aquela que acorda com medo" (DURAS, 1986, p. 73). Diante das cicatrizes da guerra, da espera e da dor, podemos considerar que seria preciso viver uma quase morte para dar lugar a algo novo, por mais precário e frágil:

Entre o momento em que abro a porta e aquele em que nos encontramos frente ao mar, eu estou morta. Numa espécie de sobrevida, percebo o verde do mar, uma praia ligeiramente alaranjada, a areia. Dentro da cabeça, a brisa salgada bloqueia o pensamento. Não sei onde ele está quando olho para o mar, mas sei que está vivo. Em algum lugar sobre a terra, respirando. Posso então deitar na areia e descansar (DURAS, 1986, p. 35).

A imagem da praia é a primeira que Duras evoca ao imaginar o retorno de Robert, criando um contraste com as cenas no interior da casa, um lugar que aparece em diversos momentos como aquele para se pensar obsessivamente sobre a morte do companheiro. Diante do mar - um espaço aberto e sem limites -, assim como diante de Robert Antelme vivo, ela consegue frear esse pensamento recorrente e deixar-se atravessar pelo entorno, pela brisa; vendo finalmente o fora.

A última cena de $A$ dor também ocorre em frente ao mar (DURAS, 1986, p. 75-79). Duras conta sobre uma viagem para a Itália em 1946, no primeiro verão de paz. Robert ainda aparece enfraquecido - não pode jogar bola nem pegar sol -, e a guerra ainda se faz presente em seu silêncio, assim como o desespero da espera no choro de M. Duras ao ouvir o nome do companheiro (DURAS, 1986, p. 78). O tempo cronológico fica embaralhado no penúltimo parágrafo, como se a autora vivesse aquele tempo mencionado em "Escrever" e no início deste artigo: o tempo após o período de espera por Robert que já não era mais 
contado. Duras (1986, p. 79) diz: "Ou então era outro ano. Outro verão. Outro dia sem vento", mas é ali, na praia, diante do "murmúrio de respiração em sono profundo" do mar, que ela deixa claro que jamais poderá esquecer o fato de Robert Antelme não ter morrido prisioneiro: "Eu sabia que ele sabia, sabia que em todas as horas, em todos os dias, eu não parava de pensar: 'Ele não morreu no campo de concentração"' (DURAS, 1986, p. 79). De forma paradoxal, ainda que não conte a passagem dos dias, ela sabe a toda hora que ele não morreu, como se, diante da quase perda que a irá assombrar para sempre, um outro tempo se instaurasse: não é o tempo da imortalidade, mas o tempo da sobrevivência, em que a possibilidade da morte talvez não seja tão terrivel quanto aquela quase morte foi.

Em sua entrevista a Foucault sobre Duras, Cixous observa que

[...] há um efeito Duras, e esse efeito Duras é que qualquer coisa de muito forte escapa. Talvez seu texto seja feito para isso, para que se deixe escapar, para que não seja retido, como seus personagens que sempre escapam para fora deles mesmos (FOUCAULT, 2001, p. 356).

De fato, talvez seja necessário que algo escape ao pensamento e à leitura por meio de uma linguagem esburacada, interrompida pela brisa, para que possamos experimentar a escrita com desespero de Marguerite Duras: uma escrita que não nos deixa esquecer a morte e, justamente por isso, pode oferecer uma saída, uma sobrevivência.

\section{MARGUeRITE DURAS, A BODY OF PAIN}

Abstract: This essay aims to observe how the undoing of the self and the ruptures regarding the rational logic of language may lead to possibilities of new subjectivities when facing situations of destitution where the body no longer seems occupied by an "I". Using mainly the text La douler [The War: A Memoir], a diary written by Marguerite Duras during World War II, but only published in 1985, in which the author narrates the time spent waiting for her companion who was detained at a concentration camp, the study attempts to reflect upon the solitude and despair of writing during this period of vigil, exploring how the writer develops these issues by using the very materiality of language.

Keywords: Marguerite Duras. Body. Writing. Language. Subjectivity.

\section{REFERÊNCIAS}

BINES, R. K. Longe dele, longe dela. RED_Revista de Ensaios Digitais, Rio de Janeiro, n. 1, 2015. Disponivel em: http://revistared.com.br/artigo/66/longedele-longe-dela. Acesso em: 12 mar. 2020.

BLANCHOT, M. O livro por vir. São Paulo: Martins Fontes, 2005.

BLANCHOT, M. O espaço literário. Rio de Janeiro: Rocco, 2011.

BLANCHOT, M. A comunidade inconfessável. Brasília: Editora da UnB; São Paulo: Lumme Editor, 2013.

DELEUZE, G. A literatura e a vida. In: DELEUZE, G. Crítica e clínica. São Paulo: Editora 34, 2011. p. 11-17. 
DURAS, M. Boas falas. Rio de Janeiro: Record, 1974.

DURAS, M. A dor. Rio de Janeiro: Editora Nova Fronteira, 1986 [1985].

DURAS, M. Escrever. Rio de Janeiro: Editora Rocco, 1994.

FOUCAULT, M. Sobre Marguerite Duras: entrevista. [out. 1975]. In: FOUCAULT, M. Ditos e escritos V. III - estética: literatura e pintura, música e cinema. São Paulo: Forense Universitária, 2001. p. 356-365.

GROSSMAN, E. Os corpos políticos de Marguerite Duras. Revista Lugar Comum, Rio de Janeiro, n. 21-22, p. 27-38, jan. 2006.

SZYMBORSKA, W. Autotomia [1972]. Disponivel em: https://razaoinadequada. com/2016/02/08/autotomia-wislawa-szymborska/. Acesso em: 14 mar. 2020. 